\title{
La participación popular en la revolución de independencia en el actual territorio argentino, 1810-1821/
}

\author{
Popular Participation in the Revolution of Independence \\ in nowadays Argentina, 1810-1821
}

\author{
Gabriel Di Meglio
}

Universidad de Buenos Aires-CONICET

La intervención política de las clases populares en el periodo independentista hispanoamericano fue muy destacada en diversos espacios integrantes de la monarquía española. Este artículo revisa las características y los motivos de esa intervención en los territorios que hoy forman parte de la República Argentina: la participación de la plebe de la ciudad de Buenos Aires y la movilización rural en el Litoral, en Salta y en Jujuy. Se ocupa, a la vez, del involucramiento de los esclavos en el proceso revolucionario en distintos espacios y del impacto de la movilización militar.

PALABRAS ClaVE: Participación popular; Revolución; Movilización; Esclavitud; Independencia.

The participation of popular classes during the independence period was relevant in different aspects within the Spanish monarchy. The present article revises the features and motives of this intervention in the territories that became part of the Argentine Republic: the plebeian participation in Buenos Aires and the rural mobilization in the Litoral, Salta and Jujuy. At the same time, analyses the involvement of the slaves in the revolutionary process and the impact of the military mobilization.

KEYwords: Popular participation; Revolution; Mobilization; Slavery; Independence. 
Una de las grandes consecuencias de la crisis del mundo hispano de principios del siglo XIX fue la irrupción plena de miembros de las clases populares -integrantes de las castas, esclavos, indígenas, campesinos y plebeyos urbanos- en las disputas políticas. Las intervenciones populares en la política tenían antecedentes nutridos, pero la coyuntura iniciada con la invasión francesa a España provocó que ahora se desencadenaran simultáneamente en diferentes espacios y que tuvieran horizontes amplios debido a la indeterminación del momento. En este artículo se repasan las características de la acción popular en los territorios que integraban el virreinato del Río de la Plata y ahora son parte de Argentina (con algunas menciones, también, a los que hoy son parte de Uruguay).

Se trata de un trabajo de síntesis, cuyo principal objetivo es presentar a un público no argentino los resultados de las investigaciones de los últimos años sobre este tema, teniendo en cuenta que la participación popular en el periodo ha recibido una atención considerable. Salvo para el caso de la ciudad de Buenos Aires, que he investigado directamente - por eso en ese apartado consigno algunas fuentes- acudo para el resto de las regiones consideradas a la producción de otros historiadores. ${ }^{1}$

\section{El bajo pueblo de Buenos Aires}

Buenos Aires fue desde la remoción del virrey en mayo de 1810 la sede de las distintas formas que adoptó el gobierno central revolucionario -que evolucionó de una junta a un triunvirato y luego a la figura de un director supremo- en las que se llamarían Provincias Unidas del Río de la Plata. La plebe de la ciudad, entonces, tuvo un diálogo directo con un poder de amplio alcance, y sus acciones políticas, como suele ocurrir en una capital, tuvieron consecuencias en todo el territorio que respondía al gobierno.

Esa heterogénea «plebe» o «bajo pueblo», dos términos empleados en la época, incluía a prácticamente todos los que no eran considerados de color blanco - los negros, los pardos, los mestizos- pero también a los numerosos blancos pobres, que no recibían antes de sus nombres el título don/doña. Plebeyos eran quienes tenían ocupaciones sin calificación, la

1 Para un panorama historiográfico y metodológico de la producción del período puede consultarse Di Meglio, 2005. Sobre cada una de las cuestiones tratadas la producción historiográfica es más amplia; sólo consigno algunas obras clave y recientes. 
mayoría de las cuales realizaban tareas manuales, incluyendo al grueso de los artesanos, los jornaleros, los peones del abasto y las panaderías, las lavanderas y planchadoras, los matarifes y los variados vendedores ambulantes, además de los que se ganaban la vida como podían y de los mendigos. $^{2}$

La presencia del bajo pueblo en la discusión pública era previa al cambio de 1810. Cuatro años antes Buenos Aires había sido capturada por los británicos y la reconquista fue planeada y ejecutada sin intervención del virrey Rafael de Sobremonte, que se había replegado hacia el interior del virreinato ante al ataque. Consumada la victoria, el funcionario procuró retornar a la capital pero en ésta se reunió un cabildo abierto que decidió impedir su vuelta y quitarle la comandancia de armas. La inédita medida se tomó en medio de la presión ejercida por una multitud congregada frente al cabildo, en la cual había muchos miembros del bajo pueblo. Los británicos volvieron unos meses más tarde y se apoderaron de Montevideo sin que Sobremonte pudiera impedirlo, provocando que otro cabildo abierto realizado en Buenos Aires lo suspendiera en sus funciones, repitiendo un acto de desobediencia. Simultáneamente, tras la primera invasión británica se creó una serie de cuerpos milicianos voluntarios, que reunieron a la mayoría de la población masculina de la ciudad. Los oficiales eran elegidos por los soldados y provenían de la elite porteña, mientras las tropas eran mayoritariamente de origen popular. Numerosos plebeyos encontraron en la milicia — donde mientras estaban en servicio recibían un salario- un trabajo estable, del cual muchos carecían en la ciudad. Y el servicio se hizo permanente: la segunda invasión inglesa llegó a Buenos Aires en 1807 y fue vencida una lucha callejera, en la llamada «Defensa». Las milicias siguieron en pie incluso tras la agresión de Bonaparte a España, que volvió a los británicos aliados y alejó el peligro de una nueva invasión. En 1809 intervinieron políticamente cuando se movilizaron a favor del virrey Santiago de Liniers — el héroe de la reconquista de 1806 - contra un movimiento juntista encabezado por peninsulares que buscaba deponerlo acusándolo por su origen francés. ${ }^{3}$ Es decir que antes de la Revolución de Mayo - en la que la presencia popular fue secundaria - la plebe contaba con una experiencia de movilización, pero a partir de ella los efectos de su acción iban a ser mayores.

2 Para una ampliación de esta cuestión véase Di Meglio, 2006; Johnson, 2011.

3 Halperin Donghi, 1978; González Bernaldo, 1990. 
La irrupción plena del bajo pueblo porteño en la lucha política se dio en 1811 debido al conflicto que se produjo dentro de la dirigencia revolucionaria: la Junta estaba dividida desde fines del año anterior entre una facción más radical y otra más moderada ligada a la figura del presidente Cornelio Saavedra y opuesta a realizar cambios significativos en el statu quo. El problema era cómo se dirimía un enfrentamiento ahora que ya no había una autoridad metropolitana para desempatar ni reglas claras sobre cómo decidir el acceso al poder. Los seguidores de Saavedra encontraron un camino para quitar de en medio a los diputados radicales de la Junta: apelar a una agitación popular. En la noche del 5 de abril de 1811 la facción de Saavedra organizó una concentración en la Plaza de la Victoria, la principal de la ciudad. Para ello «se saltó a los arrabales en busca de máquinas para ejecutar el movimiento, o como entonces se decía, se apeló a los hombres de poncho y chiripá contra los hombres de capa y de casaca». ${ }^{4}$ Algunos cientos de plebeyos de los suburbios, apoyados por el grueso de las tropas presentes en Buenos Aires - que mantuvieron un segundo plano en la acción para evitar acusaciones de un movimiento realizado por la fuerza- se presentaron ante el cabildo como «el pueblo». De este modo estaban ampliando el alcance de un concepto que hasta ese momento era socialmente limitado.

En la organización del movimiento fue decisivo el papel jugado por los influyentes alcaldes de barrio, pero también fue fundamental la consigna. No alcanzaba con dar órdenes o recurrir a vínculos clientelares para lograr una movilización numerosa, sino que las autoridades o la elite necesitaban encontrar motivos compartidos con aquellos a quienes buscaban conducir. En esta ocasión, el fundamento figuraba en el primer punto del petitorio entregado al cabildo: exigir la expulsión de todos los españoles de la ciudad. De esa manera, los peninsulares se transformaban con claridad en el principal enemigo de la revolución, que ya no eran sólo los «mandones», las autoridades coloniales. Desde mayo de 1810 la situación de los peninsulares en Buenos Aires era más intranquila que antes pero no había sufrido cambios significativos, pero eso iba a cambiar después de la asonada de abril. Si la elite era bastante cuidadosa con el tema, el resto de la sociedad porteña no tenía reparos al respecto. ${ }^{5}$

\footnotetext{
4 Núñez, 1960, I, 453.

5 Para esto, y también para todos los párrafos de este apartado donde no se consignan notas, véase Di Meglio, 2006.
} 
La animosidad popular contra los peninsulares se volcaba por un lado contra los españoles pobres. Las razones eran que los miembros de este grupo tenían ventajas por su origen: varios recibían al llegar auxilios de algunos coterráneos que ya vivían en el Río de la Plata; ocupaban las principales posiciones en el comercio minorista —más o menos la mitad de los pulperos de Buenos Aires era europea- y en las artesanías llegaban a ser maestros, mientras los oficiales y aprendices eran en su mayoría criollos o africanos; dominaban el mercado matrimonial, dado que para las mujeres plebeyas era conveniente casarse con ellos por la posibilidad de llegar a ser «decentes» o de «blanquear» su descendencia; si la justicia condenaba a un peninsular por un delito lo eximía por su «calidad» de las penas accesorias como sufrir azotes o la humillación de ser paseado por la ciudad para dar a conocer la falta públicamente, castigo que se aplicaba a los que no eran blancos pero que también fue recibido por americanos blancos, tal vez porque su origen señalaba implícitamente la imposibilidad de acreditar con total certeza limpieza de sangre. ${ }^{6}$

Los peninsulares de alta posición social, grandes comerciantes y burócratas, tenían menos contacto cotidiano con la plebe. Sin embargo, en la impugnación del conjunto de los españoles (el reclamo realizado el 5 de abril decía «todos los europeos de cualquier clase o condición») había también un rechazo a este sector. ${ }^{7}$ Desde 1811 se fue construyendo una polarización entre todos los que estaban en el bando americano, incluyendo a los africanos, contra los peninsulares. Y en el lado americano se dio cierta igualación simbólica. Así, los miembros de la plebe podían impugnar algunas jerarquías, sobre todo mediante denuncias contra los supuestos «enemigos del sistema del día», otorgándole al antiespañolismo un contenido social —y racial— más amplio.

Poco después surgió otra forma de acción popular: el motín de las tropas, que comenzó en diciembre de 1811 con el levantamiento de sargentos, cabos y soldados del regimiento de patricios. Días después de la creación de la junta en 1810 el cuerpo, que era miliciano, había sido convertido en parte del ejército de línea. Cuando la guerra empezó a alargarse, el impulso gubernamental hacia la profesionalización militar fue generando resistencias. Algunos cabos redactaron un petitorio solicitando que «se nos trate como a fieles ciudadanos libres y no como a tropa de línea»; querían

6 Pérez, 2010.

7 El petitorio en Gaceta de Buenos Ayres, 1910, II, 281-293. 
además volver a elegir sus oficiales, facultad que tenían en la época de su formación y que habían perdido. Los derechos, aunque desiguales, eran un fundamento central de la sociedad colonial y la indignación que causaba el que no se los respetara era un motor poderoso para obrar.

Un oficial amenazó con cortar la trenza que distinguía al regimiento a quienes no mantuvieran la disciplina, provocando un rechazo general: un soldado le gritó que «más fácil les sería cargarse de cadenas que dejarse pelar». El oficial respondió que si sentían la medida como una afrenta «él también estaría afrentado pues se hallaba con el pelo cortado», pero otro soldado replicó «que él tenía trajes y levitas para disimularlo».8 Así, en un movimiento que buscaba defender el derecho de los milicianos también asomó una tensión social. Los amotinados no aceptaron negociar y decidieron defender sus exigencias con las armas en la mano. A su vez, el gobierno decidió atacarlos con fuerzas leales y hubo un breve pero violento combate que terminó cuando los patricios perdieron el control de su cuartel. Once dirigentes del motín fueron fusilados y colgados.

Pero la presencia plebeya en la política no hizo sino crecer, a lo cual contribuyó la politización de los espacios urbanos y la aparición de fiestas políticas. En los mercados y en las pulperías corrían rumores, se leía la prensa en voz alta así los analfabetos podían acceder a su contenido y se discutía de política. De hecho, muchas denuncias hacia peninsulares provenían de palabras que habrían expresado en esos sitios, que podían ser corroboradas por testigos.

Los rumores jugarían un papel fundamental en la gran agitación popular de mediados de 1812, desencadenada cuando un esclavo denunció que el héroe de la Defensa contra los ingleses, Martín de Álzaga, planeaba con varios peninsulares apoderarse de Buenos Aires en connivencia con la marina de Montevideo. El gobierno procedió a detener y eliminar a los implicados: a lo largo del mes de julio, 33 españoles fueron fusilados y colgados frente a grandes multitudes. Cuando le tocó el turno a Álzaga, su ejecución fue «tan aplaudida que cuando murió se gritó por el público espectador viva la Patria varias veces», según comentó un testigo, y luego «aún en la horca lo apedrearon, y le proferían a su cadáver mil insultos, en términos que parecía un Judas de sábado santo». En ese contexto, el 8 de julio corrió el falso rumor de que los marinos de Montevideo habían desembarcado en Buenos Aires y muchos acudieron a la plaza y a los cuarteles para

8 Las citas, provenientes del juicio (hoy perdido), en Fitte, 1960, 72. 
sumarse a la defensa. Simultáneamente aparecieron distintos pasquines que anunciaban complots; muchos creían, según un contemporáneo, que el plan español era matar a los gobernantes y a muchos hombres, para luego «desterrar todos los hijos del país, los indios, las castas y los negros, porque el proyecto era que no hubiese en esta capital un solo individuo que no fuese español europeo». ${ }^{9}$ El episodio fortaleció la unidad del bando americano: un esclavo llamado Valerio dijo que «estaba con los criollos porque el Rey Indio y el Rey Negro eran la misma cosa». ${ }^{10}$

La reacción a la amenaza española fue una ola de delaciones, saqueos de viviendas y otras acciones violentas, en las cuales los miembros de la plebe jugaron un papel principal. Por las denuncias se encontraron armas escondidas en casas de varios peninsulares y un par de ellos fueron por ello ejecutados. El gobierno y el cabildo se preocuparon por la «excitación y efervescencia» del pueblo y lanzaron proclamas de pacificación, con poco éxito; de hecho las casas de dos de los integrantes del gobierno fueron atacadas por una multitud que pedía más decisión contra los enemigos y el secretario Bernardino Rivadavia fue acosado en la calle por un grupo que pedía armas para luchar contra los españoles. Las autoridades se vieron obligadas a tomar medidas para calmar el furor popular: mandaron recluir a decenas de españoles en Luján, prohibieron a los peninsulares tener pulperías - lo cual no iba a hacerse efectivo - y ordenaron que en todos los oficios debía contratarse solamente a «hijos del país». ${ }^{11}$

Junto con estas conmociones en las que la plebe actuaba de modo espontáneo y sin tutoría, hubo otras ocasiones en las que la dirigencia volvió a acudir al bajo pueblo para derribar un gobierno: ocurrió en septiembre de 1811 cuando una facción desalojó a los saavedristas del poder, y en octubre de 1812, cuando ella fue a su vez desplazada por otra. «Plebe en la plaza y tropas sosteniéndola causaron aquella novedad», se quejaba Saavedra cuando fue juzgado por su responsabilidad en el episodio de abril de 1811, «el decantado 5 y 6 de abril a que después se llama sucio y despreciable, como si los del 23 de septiembre y 8 de octubre hubiesen sido muy limpios, y decentes». ${ }^{12}$ La facción triunfante en el episodio de 1812

9 Las dos citas textuales en Beruti, 1960, IV, 3830. Los detalles de lo ocurrido en Archivo General de la Nación [AGN], X, 6-7-4, Conspiración de Álzaga.

10 Pérez, 2011.

11 Acuerdos del Extinguido Cabildo, IV, V, 1927, 261 (6 de julio de 1812).

12 "Instrucción de Saavedra a Juan de la Rosa Alba", Biblioteca de Mayo, Buenos Aires, Senado de la Nación, 1960, II, 1, 1122. 
estaba controlada por la Logia Lautaro, una sociedad secreta creada por algunos oficiales americanos que habían luchado contra Bonaparte para el ejército español y que ese mismo año habían arribado al Río de la Plata para ponerse al servicio de la Revolución, como Carlos de Alvear y José de San Martín.

El gobierno de la Logia convocó a una Asamblea que en 1813 tomó una serie de medidas importantes que afectaban a las clases populares: proclamó la libertad de vientres, por la cual todos los hijos de esclavas iban a nacer libres; confirmó la abolición del tributo indígena; dejó de jurar fidelidad a Fernando VII; suprimió los títulos de nobleza y la inquisición; prohibió la tortura. Pero al mismo tiempo la Logia impulsó políticas antipopulares. Era una pequeña clique que tomaba todas las decisiones y buscó excluir cualquier posibilidad de movilización. Realizó a la vez un gran esfuerzo para equipar a los ejércitos de pertrechos y tropas, ampliando el reclutamiento con levas masivas que provocaron descontento en la población; desde 1813 se exigió repetidas veces a las patrullas urbanas que arrestaran a los considerados vagos, a los negros libres - con excepción de «los que fuesen dueños de tiendas o talleres públicos»- y los «muchachos» - es decir, niños y adolescentes - para ser enviados al servicio de las armas. Incluso a principios de 1815 fueron movilizados los peones de las panaderías, provocando el aumento del precio de un alimento clave. En ese momento el director supremo era Alvear, quien sumó con medidas impopulares como usar una escolta personal al estilo de un virrey al descontento que causaba el aumento de la presión estatal sobre la plebe urbana. El resultado fue que en un contexto de crisis general - el ejército del Norte no cumplía las órdenes, los revolucionarios federales del Litoral habían dejado de obedecer al gobierno de las Provincias Unidas, la economía estaba muy perjudicada por la guerra, Fernando VII había regresado a su trono y el triunfo de las monarquías absolutistas llevó a la impugnación total de cualquier régimen surgido de una revolución, todos los otros centros insurgentes de América habían caído en manos realistas - hubo un levantamiento que expulsó a Alvear en abril de 1815, dirigido por el cabildo y con protagonismo de la plebe urbana, lo que uno de los damnificados llamó «el despotismo de la multitud». ${ }^{13}$

La consiguiente llegada al poder de un grupo más moderado — que sería conocido como «directorial»— implicó un cambio: el reclutamiento

13 Posadas, 1960, II, 1, 1463. 
aflojó su presión sobre la ciudad y la trasladó a otros espacios, como la campaña bonaerense. La participación porteña fue encuadrada en buena medida en los reorganizados cuerpos milicianos, divididos en tres tercios cívicos, en los cuales el segundo, que agrupaba a los habitantes más distantes del centro, y el tercero, de pardos y morenos, tenían una tropa fundamentalmente plebeya. La reorganización de la milicia en 1815 dio lugar al ascenso de algunos pulperos que en el segundo tercio cívico se convirtieron en capitanes con capacidad de movilización barrial.

El tercer tercio protagonizó un motín amplio en enero de 1819. Las autoridades lanzaron un ejército a combatir contra los disidentes del Litoral y quisieron acuartelar al tercio para defender la ciudad. Esa intención no respetaba el derecho de los milicianos de servir desde sus domicilios; el enojo de la tropa hizo que algunos sargentos, cabos y soldados organizaran la resistencia a la medida. Formados frente a los miembros del cabildo, se negaron a gritos y con disparos al aire a aceptar el acuartelamiento y se marcharon. Luego empezaron a surgir charlas y corrillos en el barrio donde vivían los negros libres, organizando una gran reunión nocturna. El soldado Santiago Manul dijo ante un grupo de changadores que el gobierno «es un ingrato, no atiende a nuestros servicios, nos quiere hacer esclavos»y convocó «a morir en defensa de nuestros derechos». ${ }^{14}$ Algunos milicianos lanzaron diatribas contra los blancos, expresando abiertamente la tensión racial. Esta impulsó a varios vecinos de otros barrios a armarse y acudir con algunas tropas a desbaratar el encuentro, lo cual puso final al motín. El gobierno, debilitado en ese momento, no castigó a ninguno de los implicados.

La impronta política miliciana se incrementaría un año más tarde: en febrero de 1820 el gobierno central se desmoronó por la victoria de los federales del Litoral en la batalla de Cepeda, tras lo cual hubo varios episodios de temor en la hasta entonces capital, durante los cuales el segundo y el tercer tercio ganaron la calle con frecuencia. En octubre de 1820, la junta de representantes de la provincia de Buenos Aires - jurisdicción que fue creada con la caída del directorio- decidió nombrar gobernador a Martín Rodríguez, quien era considerado un miembro de la impopular facción directorial que había gobernado desde 1816. El 1. e octubre de 1820, los milicianos del segundo y el tercer tercio cívico, junto con algunas tropas regulares, se pronunciaron en contra del regreso de los directoriales y

14 AGN, X, 30-3-4, Sumarios Militares, 957. 
se levantaron en armas; algunos esclavos y personas sueltas «de poncho» se sumaron al movimiento. La elite de la ciudad estaba aterrada ante el lugar que la «ínfima plebe» ocupaba en la escena pública; un oficial neutral en la contienda se sumó a las fuerzas del gobernador por el miedo a «los sanculotes despiadados, los de los ojos colorados». ${ }^{15}$ Rodríguez huyó y regresó con milicianos rurales, quienes atacaron a los cívicos acantonados en la Plaza de la Victoria. Los oficiales rebeldes y el cabildo, que había apoyado la sublevación, buscaron pactar, pero la tropa se negó a hacerlo. Mientras se llevaban a cabo negociaciones, Rodríguez atacó con su caballería y los cívicos comenzaron a resistir sin esperar órdenes. Defendieron su posición más allá de la opinión de sus líderes. La violenta lucha causó más de 300 muertos y concluyó con la derrota de la milicia urbana. Fue una matanza, que se explica porque la elite intentó eliminar toda posibilidad de desorden, para lo cual quiso sacar de la escena a quienes apelaban a la movilización popular para actuar políticamente. A la vez hubo un temor social, al saqueo, al caos: octubre de 1820 fue tal vez el momento en que la elite porteña se sintió más amenazada por la plebe urbana durante el siglo XIX. Una vez concluido el enfrentamiento, el gobierno mandó fusilar a dos cabecillas y lanzó una proclama que anunciaba una actitud intransigente contra cualquiera que quisiese «erigirse en tribuno de la plebe». Poco después los cuerpos urbanos eran disueltos: la elite triunfante buscaba eliminar las posibilidades de desorden y las vías de intervención popular en la política, tarea que no le iba a ser sencilla. ${ }^{16}$

\section{«Infelices» en armas}

En Buenos Aires la impronta popular en la Revolución fue sobre todo urbana; en cambio un poco más al norte, en las tierras ubicadas a ambos lados del río Uruguay en Entre Ríos y en la Banda Oriental, hubo una gran movilización rural. En esa zona de colonización tardía — sólo fue efectivamente ocupada por los hispano-criollos avanzado el siglo XVIII-, dedicada principalmente a la ganadería vacuna, había un conglomerado de peones y jornaleros que trabajaban en las estancias, esclavos que hacían

15 Iriarte, 1944, I, 370. Un esclavo fugado en AGN, X, 12-4-4, Solicitudes Militares.

16 Para lo ocurrido con la plebe urbana en la década de 1820 véase Di Meglio, 2006; para los años 1830 y 1840 Di Meglio, 2007. 
lo mismo y un conjunto amplio de pequeños productores independientes - pastores y labradores - que en general ocupaban terrenos sobre los que no tenían títulos. Ello dio lugar a fines de siglo a una conflictividad importante por el acceso a la tierra, sobre todo en la Banda Oriental, porque la formación de latifundios chocaba con que varias de las tierras que en teoría les pertenecían estaban ya ocupadas por productores que se sentían con derecho sobre ellas por motivos consuetudinarios. ${ }^{17}$ Esas tensiones se politizarían con la Revolución.

En 1810 los pueblos ubicados a ambas orillas del río habían aceptado primero a la junta de Buenos Aires y luego cambiaron su fidelidad hacia Montevideo, leal al Consejo de Regencia peninsular, que se convirtió en la sede del nuevo virrey del Río de la Plata y ejerció una presión creciente en la zona con el fin de obtener hombres y recursos para combatir a los revolucionarios. Llegó a impulsar la regulación de los títulos de propiedad en el ámbito rural para obtener dinero a cambio del trámite, lo que activaba la amenaza de desalojos en una zona tan sensible a esos temas. La reacción fue pronta: a principios de 1811 algunos grupos de gauchos sitiaron y luego desalojaron a los contrarrevolucionarios de los pueblos entrerrianos, a los que devolvieron a la órbita porteña. En febrero una serie de partidas se alzaron en el oeste de la Banda Oriental, declararon su adhesión a la Revolución y su oposición a Montevideo. Rápidamente emergió un líder en la región: José Artigas.

Un rasgo clave del levantamiento fue desde su inicio la hostilidad hacia los españoles. En esas zonas de colonización reciente muchos de los vecinos más poderosos eran peninsulares; generalmente se concentraban en los pueblos y en las actividades mercantiles, mientras que en la campaña y en las tareas agropecuarias eran mayoría los americanos. De ahí que la oposición entre americanos y europeos que se desarrolló a partir de 1811 fuera vista también como un enfrentamiento entre «puebleros» notables y paisanos rurales. El antiespañolismo popular permitió entonces cambios importantes en las situaciones locales a ambos lados del río Uruguay. ${ }^{18}$

No voy a ocuparme de los detalles de la revolución en la Banda Oriental, actual Uruguay. ${ }^{19}$ Sólo quiero señalar que los artiguistas fueron desarrollando una concepción de la revolución que implicaba dar poder a

17 Véase Barrán y Nahum, 1964; también Gelman, 1998.

18 Para todo lo expuesto véanse Frega, 2007 y Fradkin, 2010a.

19 Remito para ello fundamentalmente a la obra de Ana Frega citada en la bibliografía. 
todos los pueblos de la región, no sólo a las cabeceras, y contribuir a su autonomía. Creían que el Río de la Plata tenía que declarar su independencia, formar una república y organizarse como una confederación, en la cual ningún pueblo debía tener preeminencia sobre otros. Fueron así alejándose del centralismo del gobierno de Buenos Aires. Para 1814 la Banda Oriental, Entre Ríos, Corrientes y Santa Fe habían abandonado la jurisdicción porteña bajo el liderazgo de Artigas y formaron la «Liga de los Pueblos Libres». ${ }^{20}$

La movilización popular en apoyo del artiguismo, pronto llamada causa «federal», fue muy importante, en particular en Entre Ríos y sobre todo en la Banda Oriental. Se debió en buena medida a que pelear en pro de la Revolución fue para muchos luchar a favor del derecho a ocupar la tierra y a criar ganado. Los integrantes del universo popular que siguieron a Artigas mostraron según un contemporáneo «un entusiasmo frenético de la libertad» y buscaron con la lucha mejorar sus condiciones de vida, asegurar el respeto de derechos consuetudinarios de acceso a los recursos y conseguir una sociedad más justa. Durante la contienda se apropiaron en diferentes momentos de bienes ajenos y mostraron una persistente tendencia igualitarista. ${ }^{21} \mathrm{La}$ experiencia artiguista fue la más radical de la época en la región pero fue demolida por la irrupción de los portugueses desde el Brasil en 1816, que tres años más tarde se apoderaron de toda la Banda Oriental.

Dentro de los Pueblos Libres hubo otra experiencia altamente radical: la de la zona de las antiguas misiones guaraníes, en la que los indígenas tenían una larga experiencia miliciana desde el tiempo de los jesuitas. De los antiguos pueblos ocho estaban ahora en el Paraguay, siete en manos portuguesas y quince en la jurisdicción que dependía de Buenos Aires. Allí fueron surgiendo caciques que se involucraron en la disputa revolucionaria y se acercaron especialmente a la figura de Artigas, cuando varios de ellos se vieron atraídos por el ideal autonomista y por la posibilidad que daba la Revolución de vengar viejos agravios. Diversos jefes empezaron así a oponerse a los administradores y funcionarios elegidos desde Buenos Aires. El cacique Domingo Manduré atacó en 1813 al alcalde del pequeño pueblo de Mandisoví, que respondía al gobierno central, y lo removió de su cargo,

20 Véase Halperin Donghi, 1972. Para el origen del confederacionismo artiguista, Chiaramonte, 1993.

21 Frega, 2007, 269. 
dando inicio a la lucha armada entre los revolucionarios. En una proclama dijo «hermanos, sabemos que Dios nos dotó al criarnos con la libertad, y sabemos que ante él somos iguales y lo mismo ante la Ley», convocando a que «nos quitemos de mandones». Comenzó así la radicalización indígena, en cuyos pueblos se inició la expropiación de los europeos y luego la de otros pudientes; según un observador, «como ya los bienes de los Europeos se acabaron ahora todo el que tiene algo es europeo». ${ }^{22}$

Pronto surgió en la región el liderazgo de Andresito Guacurarí, ahijado de Artigas, quien en 1815 lo nombró comandante de las Misiones. Ese mismo año sus fuerzas expulsaron a los paraguayos que habían ocupado algunos pueblos al este del río Paraná. En 1816 enfrentaron la ofensiva proveniente del Brasil, simultánea a la que invadió la Banda Oriental, y al año siguiente lograron expulsar a los invasores de la zona misionera. En agosto de 1818, por indicación de Artigas, las fuerzas de Andresito ocuparon la ciudad de Corrientes, porque un cambio en el sector dirigente la había vuelto a la órbita de Buenos Aires. La entrada de un líder indígena a la ciudad causó pánico entre la elite correntina y algunos de sus miembros huyeron temiendo degüellos y violaciones. Nada de eso ocurrió, pero Andresito humilló a quienes le mostraron desprecio: mandó a varios vecinos notables a limpiar con sus manos la plaza mayor e hizo que sus mujeres e hijas bailaran con sus soldados. También liberó a los niños indígenas que muchas familias habían secuestrado para emplearlos en el servicio doméstico (dijo a los captores «recuerden en adelante que las madres indias tienen también corazón»). ${ }^{23}$ Varios criados denunciaron a sus patrones por haber escondido sus bienes: los acusados fueron requisados y si se creía que era cierto fueron expropiados. El orden se había trastocado: los sometidos estaban al mando.

Según Artigas, el objetivo de Andresito era expulsar del territorio misionero «a todos los europeos y a los administradores que hubieren, para que los naturales se gobiernen por sí, en sus pueblos». ${ }^{24}$ Es decir, reunificar la antigua provincia jesuita, incluyendo a los pueblos que estaban bajo dominio portugués y a los que dependían de Asunción. Pero ahora sin obedecer ni a jesuitas ni a ninguna autoridad suprema española, portuguesa, paraguaya o porteña. A la vez, el movimiento de Andresito expresó una

22 Fradkin, 2010a, 252-253.

23 Wilde, 2009, 339.

24 Ibidem, 352. 
abierta hostilidad hacia los blancos. Aunque su proyecto no fue apoyado por todos los pueblos guaraníes, sí logró la adhesión de muchos de los indígenas «dispersos» que habían abandonado en años anteriores las antiguas reducciones para vivir por su cuenta en el Litoral. ${ }^{25}$

Después de tres meses de ocupación, las fuerzas guaraníes abandonaron Corrientes. Volvieron a intentar recuperar los pueblos misioneros bajo control lusitano, pero fueron derrotados en 1819; Andresito cayó preso y fue enviado a Río de Janeiro, donde moriría poco después. Otros líderes guaraníes, Pantaleón Sotelo y Francisco Sity, mantuvieron la lucha y la alianza con Artigas hasta que éste fue totalmente derrotado por los portugueses y el sistema de los Pueblos Libres se desmoronó. ${ }^{26}$

\section{Los «infernales» del Norte}

Salta y Jujuy, provincias del actual Noroeste argentino, fueron escenario de otro movimiento popular de gran importancia en la época. También aquí los protagonistas populares serían plenamente rurales. El Valle de Lerma - que rodea la ciudad de Salta — había sido una zona conflictiva durante el crecimiento económico de las décadas previas, debido al choque por la tierra entre los hacendados que buscaban ampliar sus propiedades y los dinámicos pequeños productores de la zona. Unos y otros se dedicaban principalmente a criar mulas para enviar a las minas de Potosí. ${ }^{27}$

La región fue central en la guerra desde su comienzo, dado que, tras la derrota en junio de 1811 del ejército enviado desde Buenos Aires en la batalla de Huaqui, se convirtió en zona fronteriza entre los revolucionarios y sus enemigos, que controlaban el Alto Perú. En un principio el conflicto no afectó demasiado a las clases populares, más allá del reclutamiento, pero eso cambió después de Huaqui. Los revolucionarios en retirada empezaron a exigir contribuciones materiales para la causa y decidieron complicar el avance de los enemigos que lo perseguían quemando las cosechas en Jujuy, arreando ganado y obligando a los pobladores, que en su mayoría se oponían a la medida, a dejar el territorio, en lo que fue denominado más tarde el «Éxodo Jujeño». En septiembre de 1812 detuvieron su retirada y

25 Fradkin, 2010a; Machón y Cantero, 2008.

26 Véase Wilde, 2009.

27 Mata, 2008. 
libraron dos batallas victoriosas tras las que recuperaron Salta, que mientras tanto había recibido sin gran oposición la nueva tutela de las tropas del rey. Luego avanzaron sobre el Alto Perú, siendo vencidos, y en enero de 1814 los realistas volvieron a tomar Salta.

En esta ocasión les quedaban pocos partidarios — casi todos habían abandonado Salta acompañando la retirada realista del año previo- y no recibieron aportes voluntarios. Para sostenerse recurrieron a una requisa de bienes en las zonas circundantes —el Valle de Lerma- que derivó en un saqueo sistemático de estancias pero también de explotaciones medianas y pequeñas. Hubo pequeños productores que se negaron a entregar lo exigido o que atacaron luego a los realistas para recuperarlo; algunos indignados se agruparon en torno de un modesto propietario, Luis Burela, e iniciaron una resistencia armada que rápidamente sumó a miembros de cuerpos milicianos organizados en el mismo valle un año antes. Otros se movilizaron por vínculos de compadrazgo, que eran muy fuertes. Así, milicianos e irregulares iniciaron un levantamiento campesino de amplias proporciones con protagonismo popular: a los pequeños y medianos productores (propietarios, arrenderos y agregados) del Valle de Lerma se sumaron desertores del ejército regular, varios de ellos altoperuanos. Los integrantes de ese heterogéneo conjunto fueron identificados con un nombre que les dio una identidad, proveniente del Litoral y no frecuente en Salta: «gauchos». Al poco tiempo se les sumaron las milicias provenientes de la frontera con los indígenas chaqueños, que formaban parte de la Vanguardia del Ejército del Norte, dirigidas por un oficial proveniente de la elite salteña que se iba a convertir en el líder del estallido: Martín Miguel de Güemes. Los alzados cercaron la ciudad e impidieron la entrada de víveres. Los realistas terminaron abandonando en el mismo $1814 .^{28}$

Pero la victoria no puso fin a la movilización de los alzados. Por el contrario Güemes formó con ellos la división de Gauchos de Línea Infernales, que fue aprovechada por el general San Martín para establecer el plan militar con el que planeaba definir el futuro de la Revolución: mientras él prepararía un ejército para atacar a los realistas que habían recuperado Chile, la frontera con las tropas del rey en Jujuy y Salta sería defendida por estas fuerzas locales que combatirían como en el Alto Perú en guerra de guerrillas. En los años siguientes las tropas lideradas por Güemes cumplirían el cometido sanmartiniano con éxito.

28 Ibidem.. 
No sólo por este mandato se mantuvo la movilización de los gauchos. Los abusos de la ocupación no habían sido para ellos solamente un motivo de indignación coyuntural sino que causaron la politización del resentimiento antiespañol y la impugnación del orden social colonial. Así, los pequeños propietarios que se lanzaron a la lucha podían buscar asegurar sus derechos sobre las parcelas que trabajaban frente a los estancieros, los arrenderos podían impulsar su conversión en propietarios y todos podían desear abiertamente el reparto de las explotaciones de los realistas. ${ }^{29}$

Los combatientes percibieron su poderío y la capacidad de negociar que les otorgaba. También Güemes lo entendió y así se generó un vínculo estrecho, a través del cual los gauchos obtuvieron grandes beneficios. Uno fue el fuero militar, por el cual pasaron a ser juzgados por sus oficiales y no por la justicia ordinaria, con lo cual obtenían bastante indulgencia para cualquier acción de legalidad dudosa. En toda la zona empezó a ser frecuente que los hombres de Güemes se apropiaran de ganado o de otros bienes de alguna propiedad y fueran después blandamente apercibidos por sus jefes, quienes negociaban su propia ascendencia en esas ocasiones..$^{30}$ Ese «pillaje» tenía también una justificación ideológica: para los gauchos era justicia distributiva, puesto que los más pudientes debían contribuir con sus pertenencias al esfuerzo bélico. ${ }^{31}$

La elite salteña y jujeña comenzó a advertir un desafío a su hasta entonces indiscutido poder, lo que se profundizó cuando Güemes concedió a quienes estuvieran luchando el permiso para no pagar el arriendo que debían a los grandes propietarios. Como durante años los gauchos estuvieron sobre las armas casi permanentemente - hubo al menos una incursión realista anual entre 1817 y 1821, la primera de las cuales llegó a apoderarse otra vez de la ciudad de Salta—, un nutrido número dejó de pagar el canon en desmedro de los propietarios. Y muchos de los que no estaban cumpliendo un servicio activo también se refugiaron en su estatuto de gauchos para no pagar.

Al mismo tiempo hubo quienes expresaron con claridad las tensiones étnicas gritando en distintas ocasiones contra los blancos. ${ }^{32}$ Entre los gauchos había blancos pobres, indígenas y mestizos, negros y pardos. En Salta la composición de la población era heterogénea, mientras que en Jujuy la

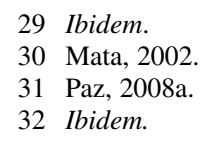


mayoría era indígena, especialmente en la Puna. Las tropas que reunió allí el revolucionario ex marqués de Tojo — no había más títulos de nobleza desde 1813 - estaban formadas sobre todo por indígenas, que lucharon en coordinación con las fuerzas de Güemes y de las guerrillas altoperuanas, en las que también la impronta indígena era predominante. Lo mismo ocurría entre los realistas, quienes en sus incursiones por la Puna impulsaron la adhesión indígena a su causa (en Yavi un cura formó con ellos un grupo llamado los «Angélicos», en oposición a los Infernales revolucionarios).

Güemes se relacionaba directamente con los gauchos, con los que había tenido un trato fluido en la frontera y en su actuación militar. Decían de él que tenía «la elocuencia de los fogones» y se hacía llamar «padre» por sus hombres, entre quienes quitó las barreras étnicas como freno al ascenso e instauró una suerte de meritocracia. A los esclavos que se sumaron a sus filas les dio la libertad. Esos rasgos y esas acciones lo hicieron sumamente popular; los gauchos lo denominaban «nuestro protector». ${ }^{33}$

La mayoría de los miembros de la elite salteña comenzó a aborrecer a Güemes por la protección a los gauchos que lesionaba sus intereses mientras la economía continuaba deteriorándose y ellos eran forzados a sostener financieramente la actividad bélica. Sin embargo, muchos se mostraban resignados al verlo como el único capaz de controlar la impronta popular. ${ }^{34}$

En 1821 Güemes fue herido de muerte por una sorpresiva incursión realista a la ciudad de Salta. Los realistas se retiraron y la elite contraria a Güemes tomó el poder. De todos modos, los gauchos seguían sobre las armas y al poco tiempo entraron en la urbe y saquearon tiendas y almacenes mientras clamaban «muerte a los cariblancos», volviendo a agitar la posibilidad de una lucha de castas. ${ }^{35}$ Sin embargo, con Güemes desapareció el único articulador efectivo de la participación popular, la cual iría perdiendo fuerza porque los realistas siguieron resistiendo en el Alto Perú hasta 1825 pero no volvieron a atacar hacia el sur. Con el fin de la guerra la elite pudo iniciar lentamente el desmantelamiento de la movilización popular que desafiaba su autoridad.

33 Ibidem, Mata, 2008.

34 Halperin Donghi, 1972.

35 Paz, 2008b. 


\section{Los esclavos y la Revolución}

Para los esclavos rioplatenses la Revolución abrió una oportunidad de acceder a la libertad. Desde un primer momento estuvieron atentos a las contradicciones de los dirigentes, quienes por un lado temían su movilización pero la necesitaban, al tiempo que sabían que existía una incoherencia entre las proclamas de libertad en las que fundaban su actuación y la conservación de la esclavitud. Entre el derecho a la libertad y el derecho de propiedad optaron por el segundo, y además desconfiaban de lo que podía generar una liberación masiva de esclavos. El triunvirato declaró en 1812 que poner fin a la esclavitud de un día para otro iba contra el derecho de los propietarios y tenía un lado peligroso, dado que se trataba de «una raza, que educada en la servidumbre no usaría la libertad sino en su propio daño». Inició, sin embargo, algunas reformas en el tema: en abril de ese año prohibió el tráfico de esclavos y dispuso que la carga de cualquier barco negrero fuera confiscada y liberada. ${ }^{36} \mathrm{La}$ medida afianzó el apoyo de los negros, esclavos y libres, a la Revolución. De hecho, un mes más tarde fue un esclavo llamado Ventura el que denunció que su amo Álzaga preparaba la conspiración que pasó a la historia con su nombre. Ventura fue premiado con la libertad y con un brazalete que decía «por fiel a la Patria». ${ }^{37}$

Los cambios antiesclavistas se profundizaron en febrero de 1813 con la Ley de libertad de vientres. En el momento, muchos creyeron que la abolición estaba cercana. Un moreno libre llamado Hilarión Gómez, por ejemplo, pidió en 1815 que su hermana no fuera vendida mientras él juntaba el dinero para comprar su libertad, y terminó su alocución diciendo «pues todo respirar el desterrar la esclavitud $»^{38}$ (sin embargo, la abolición no se produciría hasta la Constitución Nacional de 1853). Varios amos intentarían en los años sucesivos desconocer la ley y anotar a hijos de sus criadas como esclavos, lo cual fue resistido por muchas madres judicialmente. La acción de los esclavos fue crucial para asegurar el cumplimiento de la norma.

La situación revolucionaria hizo que además surgieran algunas acciones colectivas, como ocurrió en la ciudad de Mendoza en mayo de 1812, cuando un grupo de unos 30 esclavos organizó un levantamiento. El plan

36 Crespi, 2010, 27.

37 AGN, X, 6-7-4, Conspiración de Álzaga.

38 AGN, X, 8-9-4, Solicitudes Civiles y Militares, 21 de junio de 1815. 
era reunirse en las afueras, asaltar el cuartel un domingo a la noche, tomar armas y exigirle al gobierno «un decreto que les diera la libertad a todos». Los líderes eran dos músicos: Joaquín Fretes, que acababa de llegar de Chile, sabía escribir y era libre porque la revolución trasandina había abolido la esclavitud (que era económicamente menos significativa que en el Río de la Plata), y el esclavo analfabeto Bernardo, quien iba a ser el principal cabecilla porque tenía ascendencia local. Sabían de la prohibición del tráfico en Buenos Aires y corrió el rumor de que se había abolido la esclavitud en el Río de la Plata pero que las autoridades locales de Mendoza no permitían que se conociera esa declaración. Por eso los conspiradores querían garantizar su libertad y alistarse como soldados para luchar por ella, pero fueron descubiertos por la denuncia de uno de los implicados. En el juicio aparecieron también algunas intenciones más amplias: Bernardo fue acusado de haber dicho «que era necesario hacer en esta Ciudad lo que los negros de las Islas de Santo Domingo, matando a los blancos para hacerse libres». ${ }^{39}$ Así, Haití como horizonte se hacía presente, activando el temor de la elite.

Por eso, aunque la participación de los pardos y morenos libres en los cuerpos milicianos era algo habitual en la colonia, en algunos lugares hubo ciertos resquemores ante la posibilidad de movilizarlos a favor de la Revolución y más aún en el caso de los esclavos. Pero apenas la guerra empezó a extenderse se convirtió en una necesidad. Para buscar que el entusiasmo de los afectados inclinara la situación, los revolucionarios proclamaron que todos los esclavos que entraban en el ejército se convertían en libertos y al término de la guerra iban a ser libres. La medida se transformaría en uno de los principales medios de reclutamiento de los revolucionarios. $^{40}$

Hubo propietarios que mostraron su patriotismo entregando algunos esclavos para la causa, pero con eso no alcanzaba; otros rechazaron las invitaciones a seguir el camino de la donación argumentando su dependencia económica del trabajo de sus esclavos. ${ }^{41}$ En las fiestas mayas se sorteaba la libertad de algunos esclavos, que luego eran incorporados a las armas. Sin embargo, para conseguir una afluencia masiva, la Asamblea dispuso en mayo de 1813 que, como la patria estaba en peligro, era necesario formar

39 Bragoni, 2008. Las citas en las páginas 118 y 120.

40 Andrews, 1989; Blanchard, 2008.

41 Goldberg, 2010. 
un cuerpo de libertos; reconocía el «sagrado derecho de propiedad» pero consideraba que en la coyuntura los amos no tendrían problema en donar esclavos a la causa. Se requería que cada dueño entregara uno de cada tres esclavos domésticos que poseía para el servicio de las armas, uno de cada cinco que trabajaban en panaderías y talleres, y uno de cada ocho que se empleaban en tareas agrícolas. Los esclavos rescatados eran legalmente libres desde que entraban a la tropa pero, para poder gozar de esa condición, debían cumplir un servicio de cinco años o más indefinidamente hasta que se acabara el conflicto. Por lo tanto, estos «libertos» quedaron en una ambigua situación jurídica ${ }^{42}$ La libertad tenía un costo elevado, el de poner el cuerpo en la guerra, pero la mayoría de los esclavos que pudo optar prefirió ese riesgo a mantener su servidumbre. Las mujeres, por supuesto, no tuvieron esa posibilidad.

Los españoles fueron perdiendo todos sus esclavos; en 1815 la requisa para ellos se hizo general. Con el correr de los años muchos otros propietarios fueron afectados. El esfuerzo del general José de San Martín en Cuyo para organizar un ejército con el que atacar a los realistas en Chile privilegió ese aspecto: de los alrededor de 5.200 hombres que integraron el Ejército de los Andes cerca de 1.550 eran ex esclavos. ${ }^{43}$

Algunos negros ascendieron en las largas campañas sanmartinianas, en las que los libertos del Regimiento n. ${ }^{\circ} 8$ combatieron a lo largo de ocho años de Cuyo al Perú. Muchos llegaron a ser oficiales durante la guerra, aunque era más sencillo para un libre que para un esclavo (un liberto desde que entraba al ejército). Hubo casos, sin embargo, como el de Andrés Ibáñez: nacido en África, esclavo en Buenos Aires desde los 16 años, manumitido para servir como soldado y nombrado capitán por sus méritos en el servicio; después de la guerra volvió a la ciudad y compró una pulpería. ${ }^{44}$

Continuando una práctica colonial, era habitual que los cuerpos de pardos y morenos libres fueran dirigidos por oficiales de la misma condición, en particular en la milicia. En cambio, las autoridades temían que los libertos tuvieran oficiales de su mismo color, con lo cual las unidades de ex esclavos solían contar con oficiales blancos. Más allá de las grandes dificultades de la guerra, los libertos se sumaron a las empresas militares con cierto entusiasmo. Entre ellos y los otros negros se formó una identidad

42 Crespi, 2010.

43 Blanchard, 2008.

44 Bernand, 2000. Para otros casos —en la provincia de Córdoba fundamentalmente — véase Meisel, 2005. 
muy fuerte con la causa de la Patria, ligada en su origen con la posibilidad de obtener la libertad. De hecho, cuando esa opción provino del otro bando, la fidelidad a la causa tambaleó. Fue lo que ocurrió en la Banda Oriental, donde Artigas había tenido que mantener la condición de los esclavos para no terminar de ganarse la hostilidad plena de la elite montevideana. Los portugueses aprovecharon este flanco débil y en 1817 ofrecieron la libertad inmediata a los esclavos armados que se unieran a sus fuerzas, obteniendo que muchos soldados orientales en esa condición se pasaran a su lado. ${ }^{45}$

\section{La movilización militar}

Hubo dos espacios, además de los mencionados en los apartados anteriores, donde el impacto de la militarización significó un peso especialmente grande para las clases populares. Uno fue Cuyo, y en particular Mendoza, donde se organizó el Ejército de los Andes entre 1814 y 1817. El general San Martín impulsó allí una gran presión reclutadora sobre la población, especialmente la más humilde (los llamados por las autoridades «vagos y malentretenidos»). Para ordenar y disciplinar a las tropas, San Martín cuidó especialmente que el cobro de salarios fuera prioritario sobre todo otro gasto y se hiciese regularmente. Así disminuyó el tipo de acciones de apropiación de bienes por parte de las tropas tan comunes en otros espacios revolucionarios en la época. La militarización cuyana alteró completamente la vida de toda la sociedad local y dio a quienes ingresaron en el ejército una posibilidad de movilidad social ascendente, pero no conllevó una impugnación abierta del orden como en Salta o en el Litoral. ${ }^{46}$

Algo similar ocurrió en Tucumán, que estuvo fuertemente ligada con el esfuerzo bélico desde 1812 y cuya capital, San Miguel, se convirtió en 1816 en la sede permanente del Ejército del Norte, que cubría la retaguardia de las fuerzas de Güemes casi sin entrar en acción. La sociedad tucumana se conmovió con esa presencia que hizo girar todo en torno del abastecimiento a los militares. También allí fue importante la presión reclutadora sobre los «vagos». Esa militarización, de todos modos, no alteró profundamente las relaciones de poder locales. ${ }^{47}$

45 Frega, 2008.

46 Bragoni, 2005.

47 Tío Vallejo, 2002; Davio 2009. 
Participar en la guerra en cualquiera de los frentes dio lugar a nuevas identificaciones: los que integraban un regimiento por un tiempo prolongado solían tener una conciencia de pertenencia a él. Las rivalidades entre los cuerpos de los ejércitos regulares y entre éstos y las milicias eran habituales, y a menudo daban lugar a riñas. Esas identidades les permitieron a algunos oficiales construir una relación fluida con sus soldados, que luego podían actuar a favor suyo en enfrentamientos políticos. Otras veces, sin embargo, el vínculo entre oficiales y tropas fue conflictivo, por los maltratos de éstos o simplemente por la tensión resultante de la diferente extracción social de unos y otras.

La animosidad contra los oficiales, pero también las levas forzosas, el desplazamiento a lugares muy alejados de los hogares de los soldados, el hastío con la duración de la guerra y los atrasos en los pagos o en la entrega de vestuario generaban una acción concreta y extendida: la deserción. ${ }^{48}$ Cientos de combatientes abandonaban las tropas en todos los frentes, en general de manera individual o en pequeños grupos, y tomaban distintos caminos: volvían a su tierra, se conchababan para trabajar en la zona en la que estaban sirviendo, formaban partidas de bandidos que pululaban por las áreas rurales o se instalaban del otro lado de las fronteras con los indígenas independientes de las vastas llanuras del Chaco o la Pampa. A su vez, éstos se fueron integrando progresivamente, en la última parte de la década de 1810, a las luchas entre Buenos Aires y los Pueblos Libres artiguistas, reactivando la conflictividad fronteriza que se había calmado en la última parte del siglo XVIII. ${ }^{49}$

Al final del periodo, las evaluaciones populares sobre la Revolución estuvieron en varios casos cargadas de frustración, por los efectos devastadores de la guerra y por las aspiraciones incumplidas pese al esfuerzo realizado. Muchos miembros de las clases populares pasaron largas temporadas en condiciones muy duras y sentían que seguían en el mismo lugar que antes. De ahí la aparición de lamentos: «el que tiene es don Julano / y el que perdió se amoló: / sin que todos los servicios / que a la Patria le emprestó / lo libren de una roncada / que le largue algún pintor». ${ }^{50}$

Más allá de que las transformaciones resultaran más limitadas de lo que algunos soñaron, lo cierto es que el fin de la guerra de independencia

48 Véanse Di Meglio, 2006; Rabinovich, 2011.

49 Para la intervención de los indígenas véase Ratto, 2008.

50 "Diálogo patriótico interesante", en Hidalgo, 1967, 48. 
en 1821 no significó el regreso a una realidad previa sino el inicio de una nueva, surgida de las conmociones de la década y por lo tanto moldeada, entre otras cosas, por la participación popular.

Recibido el 14 de julio de 2011 Aceptado el 30 de septiembre de 2011

\section{Bibliografía}

Acuerdos del Extinguido Cabildo, Buenos Aires, Archivo General de la Nación, 1927, serie IV, V.

Andrews, George: Los afroargentinos de Buenos Aires, Buenos Aires, Editorial de la Flor, 1989.

Barrán, José Pedro y Nahum, Benjamín: Bases económicas de la revolución artiguista, Montevideo, Ediciones de la Banda Oriental, 1964.

Bernand, Carmen: «La población negra de Buenos Aires (1777-1862)», en Quijada, Mónica, Bernand, Carmen y Schneider, Alejandro: Homogeneidad y Nación. Con un estudio de caso: Argentina, siglos XIX y XX, Madrid, Consejo Superior de Investigaciones Científicas, 2000, 93-140.

Beruti, Juan Manuel: «Memorias curiosas», en Biblioteca de Mayo, Buenos Aires, Senado de la Nación, 1960, IV, 3647-4150.

Blanchard, Peter: Under the Flags of Freedom: Slave Soldiers and the Wars of Independence in Spanish South America, Pittsburgh, University of Pittsburgh Press, 2008.

Bragoni, Beatriz: «Guerreros virtuosos, soldados a sueldo. Móviles de reclutamiento militar durante el desarrollo de la guerra de independencia», en Dimensión Antropológica, Año 12, 35, México, 2005, 95-138.

Bragoni, «Esclavos, libertos y soldados: la cultura política plebeya en Cuyo durante la Revolución», en Fradkin, Raúl (ed.), ¿Y el pueblo dónde está? Contribuciones para una historia popular de la revolución de independencia en el Río de la Plata, 2008, 107-150.

Chiaramonte, José Carlos: «El federalismo argentino en la primera mitad del siglo $\mathrm{XIX»,} \mathrm{en} \mathrm{Carmagnani,} \mathrm{Marcello} \mathrm{(coord.):} \mathrm{Federalismos} \mathrm{latinoamericanos:}$ México/Brasil/Argentina, México, FCE, 1993, 81-127.

Crespi, Liliana: «Ni esclavo ni libre. El status del liberto en el Río de la Plata desde el periodo indiano al republicano», en Mallo, Silvia y Telesca, Ignacio (eds.), «Negros de la Patria». Los afrodescendientes en las luchas por la independencia en el antiguo Virreinato del Río de la Plata, Buenos Aires, SB, 2010, 15-37. 
Davio, Marisa: «El proceso de militarización durante la Revolución. Tucumán, 1812-1819», en López, Cristina (comp.), Identidades, representación y poder entre el antiguo régimen y la revolución: Tucumán, 1750-1850, Rosario, Prohistoria, 2009, 83-102.

Di Meglio, Gabriel: «La historia popular de la Argentina del siglo XIX», Nuevo Topo. Revista de historia y pensamiento crítico, Buenos Aires, 1, 2005, 55-76.

Di Meglio, ¡Mueran los salvajes unitarios! La Mazorca y la política en tiempos de Rosas, Buenos Aires, Sudamericana, 2007.

Di Meglio, ;Viva el bajo pueblo! La plebe urbana de Buenos Aires y la política entre la Revolución de Mayo y el rosismo, Buenos Aires, Prometeo, 2006.

Fitte, Ernesto: El motín de las trenzas, Buenos Aires, Fernández Blanco, 1960.

Fradkin, Raúl: «Cultura política y acción colectiva en Buenos Aires (1806-1829)», en Fradkin (ed.), ¿Y el pueblo dónde está? Contribuciones para una historia popular de la revolución de independencia en el Río de la Plata, Buenos Aires, Prometeo, 2008, 27-65.

Fradkin, «La revolución en los pueblos del litoral rioplatense», Estudios IberoAmericanos, 36, 2, 2010a, 242-265.

Fradkin, «Las formas de hacer la guerra en el litoral rioplatense», en Bandieri, Susana (comp.): La historia económica y los procesos de independencia en la América hispana, Buenos Aires, Prometeo, 2010b, 167-213.

Frega, Ana: «Los 'infelices' y el carácter popular de la Revolución artiguista», en Fradkin (ed.), ¿Y el pueblo dónde está? Contribuciones para una historia popular de la revolución de independencia en el Río de la Plata, Buenos Aires, 2008 ${ }^{\mathrm{a}}$, 151-175.

Frega, Pueblos y soberanía en la revolución artiguista. La región de Santo Domingo Soriano desde fines de la colonia hasta la ocupación portuguesa, Montevideo, Ediciones de la Banda Oriental, 2007.

Gaceta de Buenos Ayres, edición facsimilar, Buenos Aires, Junta de Historia y Numismática, 1910, siete tomos.

Gelman, Jorge: Campesinos y estancieros. Una región del Río de la Plata a fines de la época colonial, Buenos Aires, Los Libros del Riel, 1998.

Goldberg, Marta: «Afrosoldados de Buenos Aires en armas para defender a sus amos», en Mallo, Silvia y Telesca, Ignacio (eds.), «Negros de la Patria». Los afrodescendientes en las luchas por la independencia en el antiguo Virreinato del Río de la Plata, Buenos Aires, SB, 2010, 39-63.

González Bernaldo, Pilar: «Producción de una nueva legitimidad: ejército y sociedades patrióticas en Buenos Aires entre 1810 y 1813», en AA.VV., Imagen y recepción de la Revolución Francesa en la Argentina. Buenos Aires, Grupo Editor Latinoamericano, 1990, 27-51. 
Halperin Donghi, Tulio: «Militarización revolucionaria en Buenos Aires, 18061815», en su El ocaso del orden colonial en Hispanoamérica, Buenos Aires, Sudamericana, 1978, 121-158.

Halperin Donghi, Revolución y guerra. Formación de una elite dirigente en la Argentina criolla, Buenos Aires, Siglo XXI, 1972.

Hidalgo, Bartolomé: Cielitos y diálogos patrióticos, Buenos Aires, Centro Editor de América Latina, 1967.

Iriarte, Tomás de: Memorias, Buenos Aires, Sociedad Impresora Americana, 1944, I.

Johnson, Lyman: Workshop of revolution: Plebeian Buenos Aires and the Atlantic World, 1776-1810, Duke University Press, 2011.

Machón, Jorge y Cantero, Oscar: 1815-1821: Misiones provincia federal, Posadas, Editorial Universitaria de Misiones, 2008.

Mata, Sara: «La guerra de independencia en Salta y la emergencia de nuevas relaciones de poder», Revista Andes, 13, Salta, 2002, 113-144.

Mata, Los gauchos de Güemes. Guerras de independencia y conflicto social, Buenos Aires, Editorial Sudamericana, 2008.

Meisel, Seth: «Manumisión militar en las Provincias Unidas de Río de la Plata», en Ortiz Escamilla, Juan (comp.), Fuerzas militares en Iberoamérica, siglos XVIII y XIX. México, El Colegio de México/El Colegio de MichoacánUniversidad Veracruzana, 2005, 165-177.

Núñez, Ignacio: «Noticias históricas», en Biblioteca de Mayo, Buenos Aires, Senado de la Nación, 1960, I, 197-511.

Paz, Gustavo: «'El orden es el desorden'. Guerra y movilización campesina en la campaña de Jujuy, 1815-1821», en Fradkin, Raúl y Gelman, Jorge (comps.): Desafíos al orden. Política y sociedades rurales durante la Revolución de Independencia, Rosario, Prohistoria Ediciones, 2008a, 83-101.

Paz, «Reordenando la campaña: la restauración del orden en la campaña de Salta y Jujuy, 1822-1825», en Fradkin (ed.), ¿Y el pueblo dónde está?, Contribuciones para una historia popular de la revolución de independencia en el Río de , 2008b, 209-222.

Pérez, Mariana: En busca de mejor fortuna. Los inmigrantes españoles en Buenos Aires del Virreinato a la Revolución de Mayo, Buenos Aires, Prometeo, 2010.

Pérez, «¡Viva España y mueran los criollos! La conspiración de Álzaga de 1812», en Alabart, Mónica; Fernández, María Alejandra y Pérez, Mariana (comps.), Buenos Aires una sociedad que se transforma. Entre la colonia y la Revolución de Mayo, Buenos Aires: Prometeo/UNGS, 2011, en prensa.

Posadas, Gervasio: «Autobiografía», en Biblioteca de Mayo, Buenos Aires, Senado de la Nación, 1960, II, 1, 1405-1502. 
Rabinovich, Alejandro: «El fenómeno de la deserción en las guerras de la revolución e independencia del Río de la Plata, 1810-1829», E.I.A.L., 22, 1, Tel Aviv, 2011.

Ratto, Silvia: «Los indios y la revolución en el Río de la Plata. El proceso independentista de Pampa y Chaco», en Bragoni, Beatriz y Mata, Sara (comps.), Entre la colonia y la república. Insurgencias, rebeliones y cultura política en América del Sur, Buenos Aires, Prometeo Libros, 2008, 143-168.

Tío Vallejo, Gabriela: Antiguo Régimen y Liberalismo. Tucumán, 1770-1830, Tucumán, Universidad Nacional de Tucumán, 2001.

Wilde, Guillermo: Religión y poder en las misiones de guaraníes, Buenos Aires, SB, 2009. 